\title{
Fabrication of GO/PAN Nanofiber Membrane Grafted With Chitosan As Efficient Adsorbent For Dye Removal
}

\section{Yanran Lu}

Tiangong University

Wen Zhang ( $\nabla$ zhangwen2050@hotmail.com )

Tiangong University https://orcid.org/0000-0001-9739-9799

\section{Mei Wang}

Tiangong University

\section{Hua Zhang}

Tiangong University

Jiahui Li

Tiangong University

\section{Wenhao Luo}

Tiangong University

\section{Research Article}

Keywords: Nanofiber membrane, Electrospinning, Polyacrylonitrile, Graphene Oxide, Chitosan, Sunset Yellow

Posted Date: October 12th, 2021

DOl: https://doi.org/10.21203/rs.3.rs-962554/v1

License: (9) This work is licensed under a Creative Commons Attribution 4.0 International License. Read Full License

Version of Record: A version of this preprint was published at Journal of Polymers and the Environment on February 25th, 2022. See the published version at https://doi.org/10.1007/s10924-022-02393-6. 


\title{
Fabrication of GO/PAN Nanofiber Membrane Grafted with Chitosan as Efficient Adsorbent for Dye Removal
}

\author{
Yanran Lu ${ }^{\mathrm{a}, \mathrm{b}} \cdot$ Wen Zhang ${ }^{\mathrm{a},{ }^{*}} \cdot$ Mei Wang ${ }^{\mathrm{a}} \cdot$ Hua Zhang ${ }^{\mathrm{a},{ }^{*}} \cdot \mathrm{Jiahui} \mathrm{Li}^{\mathrm{a}} \cdot$ Wenhao Luo ${ }^{\mathrm{a}}$ \\ ${ }^{a}$ State Key Laboratory of Separation Membranes and Membrane Processes, School of Materials \\ Science and Engineering, Tiangong University, Tianjin 300387, China; \\ ${ }^{b}$ National Synchrotron Radiation Laboratory, Anhui Provincial Engineering Laboratory of Advanced \\ Functional Polymer Film, CAS Key Laboratory of Soft Matter Chemistry, University of Science and \\ Technology of China, Hefei 230026, China \\ *Corresponding author. E-mail address: zhangwen2050@hotmail.com, hua1210@126.com \\ Tel.: +86 13516155156
}

\begin{abstract}
The adsorption is widely used to remove dyes from wastewater because of its low cost, simple preparation, and environmental friendliness. However, the existing adsorbents suffer from difficult recycling, inconvenient use, and low regeneration rate. In this study, polyacrylonitrile (PAN) and graphene oxide (GO) was mixed for electrospinning GO/PAN nanofiber membrane and then chitosan (CS) was grafted to obtain CS-GO/PAN nanofiber membrane. CS-GO/PAN membrane were characterized with FE-SEM, EDX, FT-IR and, WCA. The effects of membrane types, dosage, solution $\mathrm{pH}$ on the removal of dye sunset yellow (SY) were systematically investigated. The results showed that more than $80 \%$ of SY were removed within 15 min at $\mathrm{pH} 2$ using $100 \mathrm{mg}$ CS-GO/PAN membrane. Adsorption kinetic data were fitted well with the pseudo-second-order model and adsorption equilibrium achieved within $240 \mathrm{~min}$. The isotherm study followed the Langmuir model with the actual maximum adsorption capacity of $211.54 \mathrm{mg} / \mathrm{g}$. After 5 adsorption-desorption cycles, the adsorption efficiency and the desorption efficiency of CS-GO/PAN were over $90 \%$ and $93 \%$, respectively. Moreover, the membrane recovered easily from the water while its integrity was still maintained. The CS-GO/PAN membrane demonstrates the virtue of high adsorption capacity, easy operation, and good reusability, which could be considered as a promising material for adsorbing dyes in wastewater.

Keywords Nanofiber membrane $\cdot$ Electrospinning $\cdot$ Polyacrylonitrile $\cdot$ Graphene Oxide $\cdot$

Chitosan $\cdot$ Sunset Yellow
\end{abstract}




\section{Introduction}

Dyes are widely used in various industries producing food, textiles, printing, leather, and cosmetics ${ }^{[1,2]}$. Dye wastewater is one of the most difficult industrial wastewaters to treat because of its stable composition, high chroma, and high concentration of organic matter ${ }^{[3]}$. The common methods in the treatment of dye wastewater include coagulation, electrolysis, photocatalytic degradation, biodegradation, ultrafiltration, adsorption and etc ${ }^{[4-9]}$. However, the majority are complicated and expensive. Among these technologies, the adsorption has attracted much attention due to its simple design, easy operation, low cost, and wide range of adsorbent sources ${ }^{[10,11]}$.

Pollutants in the water are adsorbed by materials with a large specific surface area and porous structure, or polar groups on the surface of materials. Graphene oxide (GO) is a two-dimensional (2D) carbon-based with atomic thickness and large planar size ${ }^{[12]}$. High adsorption capacity, mechanical flexibility, and chemical stability is given by its unique structure ${ }^{[13,14]}$. The GO activated carbon (GOAC) composite synthesized by the one-step mixing method has an adsorption capacity of $147 \mathrm{mg} / \mathrm{g}$ for Crystal Violet ${ }^{[15]}$. An alginate/gelatin/graphene oxide (SGGO) composite aerogel was prepared by a "hydrophilic assembly-sustained release gelation" method, showed an ordered fishing net-like microstructure, and the maximum adsorption capacity for Methylene blue and Congo red was 322.6 $\mathrm{mg} / \mathrm{g}$ and $196.8 \mathrm{mg} / \mathrm{g}$ respectively. ${ }^{[16]}$ As a non-toxic and environmentally benign amino polysaccharide, chitosan (CS) contains a large number of amino(- $\left.\mathrm{NH}_{2}\right)$ and hydroxyl (-OH) functional groups, which provides active sites for the adsorption of dyes and other pollutants ${ }^{[17,18]}$. However, CS dissolves slowly in an acidic environment. The practicability of CS was significantly improved by compounding with other materials. Zheng et al. ${ }^{[19]}$ prepared dialdehyde microfibrillated cellulose (DAMFC), and then DAMFC was compounded with CS through the Schiff Base. The addition of DAMFC resulted in drastically improved stability of CS in dye solution.

The combination of GO and CS enlarged the specific surface area as well as active sites of the adsorbent. The magnetic CS/GO (MCGO) nanocomposite was prepared by slowly adding CS/GO suspension into the iron oxide magnetic nanoparticle dispersion. The maximum adsorption capacity of MCGO for Methyl Orange reached $398.08 \mathrm{mg} / \mathrm{g}^{[20]}$. Although excellent adsorption property of these dispersed adsorbents was reported, they usually lack enough durability and recovery, and lead to the 
generation of secondary pollution.

Electrospinning nanofiber membranes have been extensively studied due to their advantages of large specific surface area, easy recovery, excellent mechanical properties, and high recycling rate ${ }^{[21-}$ 23]. Polyacrylonitrile (PAN) has chemical stability, the resistance of corrosion and biodegradation, hence used to prepare fiber membrane frequently ${ }^{[24,25]}$. The abundant nitrile groups $(\mathrm{C} \equiv N)$ on the surface of PAN fiber can be easily converted into active groups by chemical reaction ${ }^{[26]}$. Oxime grafted PAN nanofiber membrane with high grafting percent (79\%) showed good adsorption to Methylene Blue, Rhodamine B and Safranin $\mathrm{T}^{[27]}$. Sunset yellow (SY) is mainly used for tinting drugs and food (The details are shown in Table 1). Long-term or a one-time large intake of SY leads to symptoms such as allergies, diarrhea, and risk of cancer ${ }^{[28]}$. However, there are still very few reports on successful adsorption of SY in wastewater though electrospinning nanofiber membrane.

Herein, the preparation of CS-GO/PAN nanofiber membrane by electrospinning and chemical grafting technology was presented, which overcomes the shortcomings of poor acid resistance of CS. The adsorption characteristics of the CS-GO/PAN were emphatically discussed for dye pollutants represented by SY. Investigate the influence of membrane types, dosage, solution $\mathrm{pH}$ on the adsorption, and utilize related models to analyze the isotherm and kinetic adsorption mechanism. Besides, the desorption process and recycling were discussed.

Table 1 Chemical structure and properties of SY

\begin{tabular}{cc}
\hline Sunset Yellow & Detail \\
\hline Chemical formula & $\mathrm{C}_{16} \mathrm{H}_{10} \mathrm{~N}_{2} \mathrm{Na}_{2} \mathrm{O}_{7} \mathrm{~S}_{2}$ \\
Class & $\mathrm{Azo}$ \\
Color index & 15985 \\
Molecular weight $(\mathrm{g} / \mathrm{mol})$ & 452.38 \\
$\lambda_{\max }(\mathrm{nm})$ & $482 \pm 2$ \\
Molecular structure &
\end{tabular}




\section{Materials and methods}

\section{Materials}

$\mathrm{GO}(>95 \mathrm{wt} \%)$ was obtained from Suzhou Hengqiu Graphenechina Technologies Co., Ltd. CS and PAN were provided by Sinopharm Chemical Reagent Co., Ltd and Tianjin Yongda Chemical Reagent Co., Ltd, respectively. N, N -dimethylformamide (DMF, 99.5\%) was purchased from Shandong Qilu Petro-Chemical Engineering Company. Sodium hydroxide $(\mathrm{NaOH})$ and hydrochloric acid $(\mathrm{HCl})$ were purchased from Tianjin Sailboat Chemical Reagent Technology Co., Ltd. 1-Ethyl-3-(3dimethylaminopropyl)carbodiimide (EDC) and N-Hydroxy succinimide (NHS) were obtained from Shanghai Macklin Biochemical Co., Ltd. Polyethylene glycol (PEG, 6000) was purchased from Aladdin Chemical Co., Ltd.

\section{Preparation of the CS-GO/PAN nanofiber membranes}

The preparation process and adsorption activity of CS-GO/PAN nanofiber membranes were presented in Fig. 1.

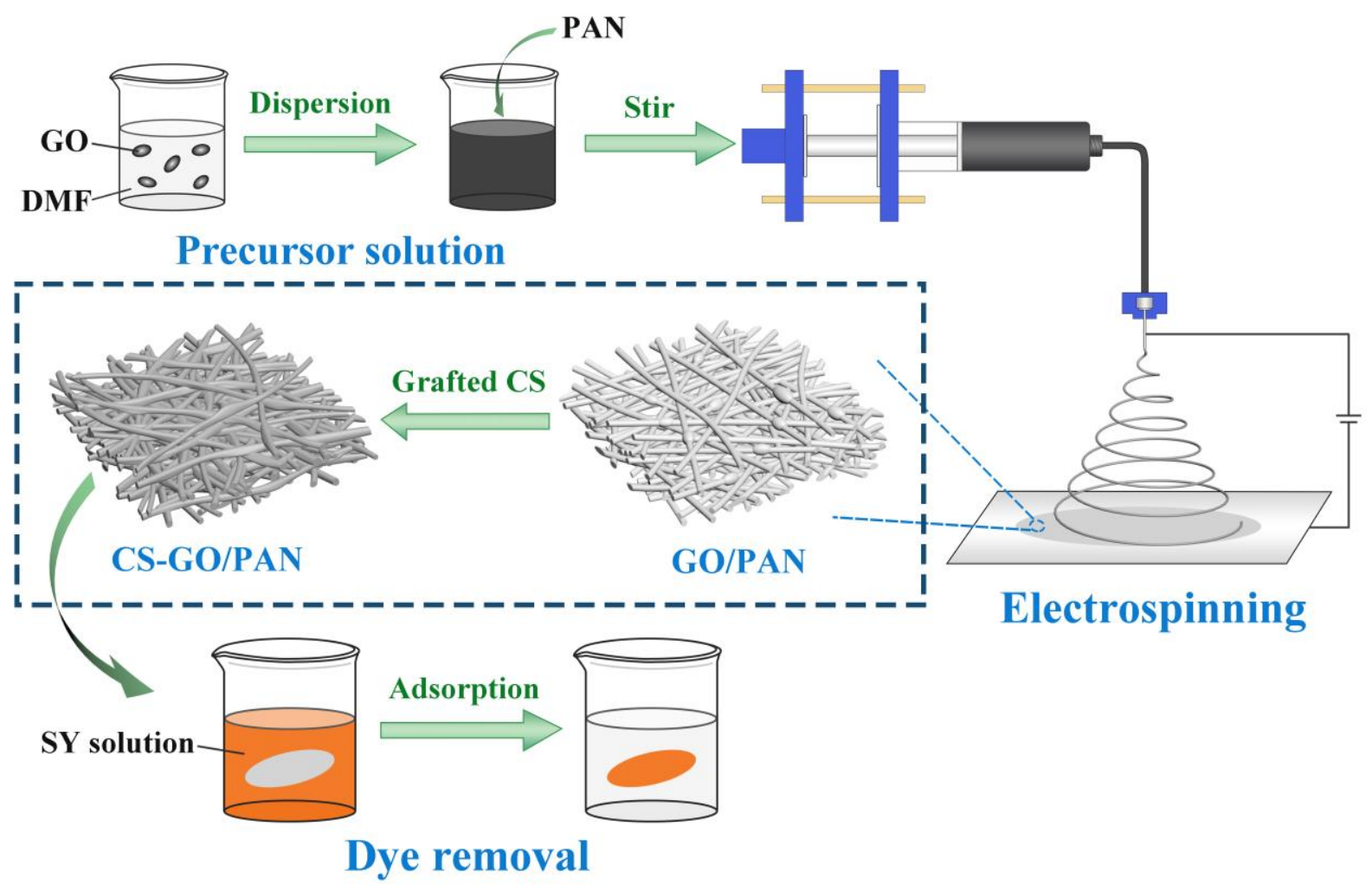

Fig. 1 Schematic of CS-GO/PAN nanofiber membranes preparation process and adsorption activity 
GO/PAN nanofiber membranes were obtained by electrospinning. A homogeneous electrospinning precursor solution of PAN and GO was prepared by adding $0.40 \mathrm{wt} \%$ GO into DMF and sonicated at $4^{\circ} \mathrm{C}$ for dispersing uniformly. PAN (15 wt\%) was added to the above solution and mixed by a magnetic stirrer for $10 \mathrm{~h}$. The precursor solution was then injected into a $5 \mathrm{~mL}$ syringe equipped with 21-gauge needle. The spinning parameters were set to the voltage of $20 \mathrm{kV}$, the collect distance between the needle tip and aluminum foil of $15 \mathrm{~cm}$, the temperature of $\left(30 \pm 5^{\circ} \mathrm{C}\right)$, the humidity of $(30 \pm 5 \%)$. The GO/PAN nanofiber membrane was collected for $4 \mathrm{~h}$ continuous electrospinning at a feed rate of $1 \mathrm{~mL} / \mathrm{h}$.

GO/PAN membrane was modified by grafting with CS. GO/PAN was hydrolyzed in $2.5 \mathrm{M} \mathrm{NaOH}$ at $40^{\circ} \mathrm{C}$ for $4 \mathrm{~h}$, and then put into $2 \mathrm{M} \mathrm{HCl}$ for $1 \mathrm{~h}$. Take it out, wash with water until neutral and dry. $\mathrm{CS}(0.2 \mathrm{wt} \%, 0.5 \mathrm{wt} \%, 0.7 \mathrm{wt} \%$ and $1 \mathrm{wt} \%)$ was added to a beaker containing $100 \mathrm{~mL}$ water, and then the $\mathrm{pH}$ of the solution was adjusted to 5 by $\mathrm{HCl}$ to dissolve it. $0.5 \mathrm{wt} \%$ hydrolyzed GO/PAN membrane was added to CS solution with a small amount of EDC and NHS. Then beaker was sealed and kept at $35^{\circ} \mathrm{C}$ with shaking for $16 \mathrm{~h}$, and an amide bond was formed between the membrane surface and CS. The solution was adjusted $\mathrm{pH}$ to 8 with $\mathrm{NaOH}$, and then the pure sample was obtained by dialysis, concentration with PEG, and dry. The various samples mentioned above are defined in Table 2.

Table 2 The recipe of the nanofiber membranes

\begin{tabular}{ccccc}
\hline Simple & DMF $(\mathrm{mL})$ & PAN $(\mathrm{g})$ & GO $(\mathrm{mg})$ & CS $(\mathrm{g})$ \\
\hline PAN & 10 & 1.5 & 0 & 0 \\
GO/PAN & 10 & 1.5 & 40 & 0 \\
$0.2 \mathrm{CS}-\mathrm{GO} / \mathrm{PAN}$ & 10 & 1.5 & 40 & 0.2 \\
$0.5 \mathrm{CS}-\mathrm{GO} / \mathrm{PAN}$ & 10 & 1.5 & 40 & 0.5 \\
$0.7 \mathrm{CS}-\mathrm{GO} / \mathrm{PAN}$ & 10 & 1.5 & 40 & 0.7 \\
1.0 CS-GO/PAN & 10 & 1.5 & 40 & 1.0 \\
\hline
\end{tabular}

\section{Characterization}

The surface morphologies of PAN, GO-PAN and CS-GO/PAN nanofiber membranes were studied by FE-SEM (Hitachi S-4800, Japan). The Energy Dispersive X-ray spectrometry (EDX) was used to characterize the element information. The average diameters of nanofiber membranes were measured from FE-SEM images by Nano Measure software $(n=100)$. The chemical groups of membranes are analyzed by Fourier Transform Infrared Spectroscopy (FT-IR, Thermofisher, Nicolet iS50, China) in the range of $500-4000 \mathrm{~cm}^{-1}$ spectra. The dynamic water contact angle of the sample surface measured 
by the WCA (DSA-100, Kruss, Germany) reflects the hydrophilicity.

\section{Adsorption and regeneration experiments}

The performance of adsorbents was studied by using the batch method. Batch assays were carried out at a shaking rate of $120 \mathrm{rpm}$ during the experiment. Firstly, $100 \mathrm{mg}$ of each sample was added to $100 \mathrm{mg} / \mathrm{L} \mathrm{SY}$ at $\mathrm{pH} 6.4$ and shaken at $35^{\circ} \mathrm{C}$ for $480 \mathrm{~min}$ to determine the effect of adding $\mathrm{GO}$ and $\mathrm{CS}$ on the adsorption. Secondly, the optimal adsorption dosage was evaluated between 50 to $400 \mathrm{mg}$ in $100 \mathrm{mg} / \mathrm{L} \mathrm{SY}$. $\mathrm{NaOH}$ and $\mathrm{HCl}$ were used to adjust the $\mathrm{pH}$ of the solution through a digital $\mathrm{pH}$ meter. The effect of $\mathrm{pH}$ was studied in the range of $1-10$. The kinetics of $100 \mathrm{mg} / \mathrm{L}$ and $150 \mathrm{mg} / \mathrm{L} \mathrm{SY}$ were discussed at different contact times $(0-480 \mathrm{~min})$, and the wave spectrum of $100 \mathrm{mg} / \mathrm{L} \mathrm{SY}$ at the corresponding time was measured. For the adsorption isotherm experiment, the data of different initial concentrations $(0-2000 \mathrm{mg} / \mathrm{L})$ were collected to explore the maximum adsorption capacity. Finally, the membranes were immersed in $1 \mathrm{M} \mathrm{NaOH}$ for $60 \mathrm{~min}$ and washed with water to separate the adsorbed dye. Five adsorption-desorption cycles were carried out to evaluate the reusability. The concentration of SY was determined by a UV-Vis spectrophotometer (HNY-200B, Honour, China) at the maximum absorption wavelength of $483 \mathrm{~nm}$.

The adsorption capacity $\left(q_{e}, \mathrm{mg} / \mathrm{g}\right)$ and the adsorption efficiency $(E, \%)$ at equilibrium were calculated by Eq. 1 and 2, respectively ${ }^{[29]}$. In addition, the desorption efficiency $(D E, \%)$ was used to characterize the desorption effect of the membranes (Eq. 3).

$q_{e}=\left(C_{0}-C_{e}\right) V / m$

$E=\left(C_{0}-C_{e}\right) / C_{0} \times 100 \%$

$D E=q_{e}^{\prime} / q_{e} \times 100 \%$

where $C_{0}$ and $C_{e}(\mathrm{mg} / \mathrm{L})$ are the initial and equilibrium concentrations of SY, respectively. $V(\mathrm{~L})$ is the volume of the solution and $m(\mathrm{~g})$ is the mass of adsorbents. $q^{\prime}(\mathrm{mg} / \mathrm{g})$ is the amount of SY after desorption.

\section{Results and discussion}

\section{Characterization of nanofiber membranes}

The morphology and diameter distribution of PAN, GO/PAN and 0.7CS-GO/PAN nanofiber membranes were shown in Fig. 2. Pure PAN nanofiber exhibited uniform, smooth and randomly 
oriented filaments (Fig. 2 a, b). The average diameter of fiber was $287 \pm 21 \mathrm{~nm}$ (Fig. 2 c). The nodes emerged on the nanofibers after adding GO, indicating that GO was wrapped in the fibers (Fig. 2 d, e), which has also been confirmed by other researchers ${ }^{[30,31]}$. The average diameter of GO/PAN was $239 \pm 27 \mathrm{~nm}$ (Fig. 2 f). A possible reason for diameter decrement was that lamellar GO leads to unstable spinning jets during the electrospinning process, which enhanced the stretching of the jets. 0.7CSGO/PAN nanofibers shown a certain degree of bending and adhesion (Fig. $2 \mathrm{~g}$ ). In addition, fibers of 0.7CS-GO/PAN were covered with abundant CS, and a small amount of CS layer even blocked the gap between the fibers (Fig. $2 \mathrm{~h}$ ), which resulted in the average diameter of $0.7 \mathrm{CS}-\mathrm{GO} / \mathrm{PAN}(\mathrm{D}=308 \pm 39$ nm, Fig. 2 i) higher than that of PAN and GO/PAN. The diameter distribution analysis was proved that the distribution of GO/PAN was more dispersed than pure PAN, which was attributed to the existence of nodes with larger diameter while the PAN fiber wrapped with GO became thinner due to stretching. Besides, the digital photo in Fig. 2 showed that the surface of CS-GO/PAN was rougher than PAN. A rough surface can improve the wettability of the membrane ${ }^{[32]}$, which is consistent with the experimental results of the WCA in the following text. 

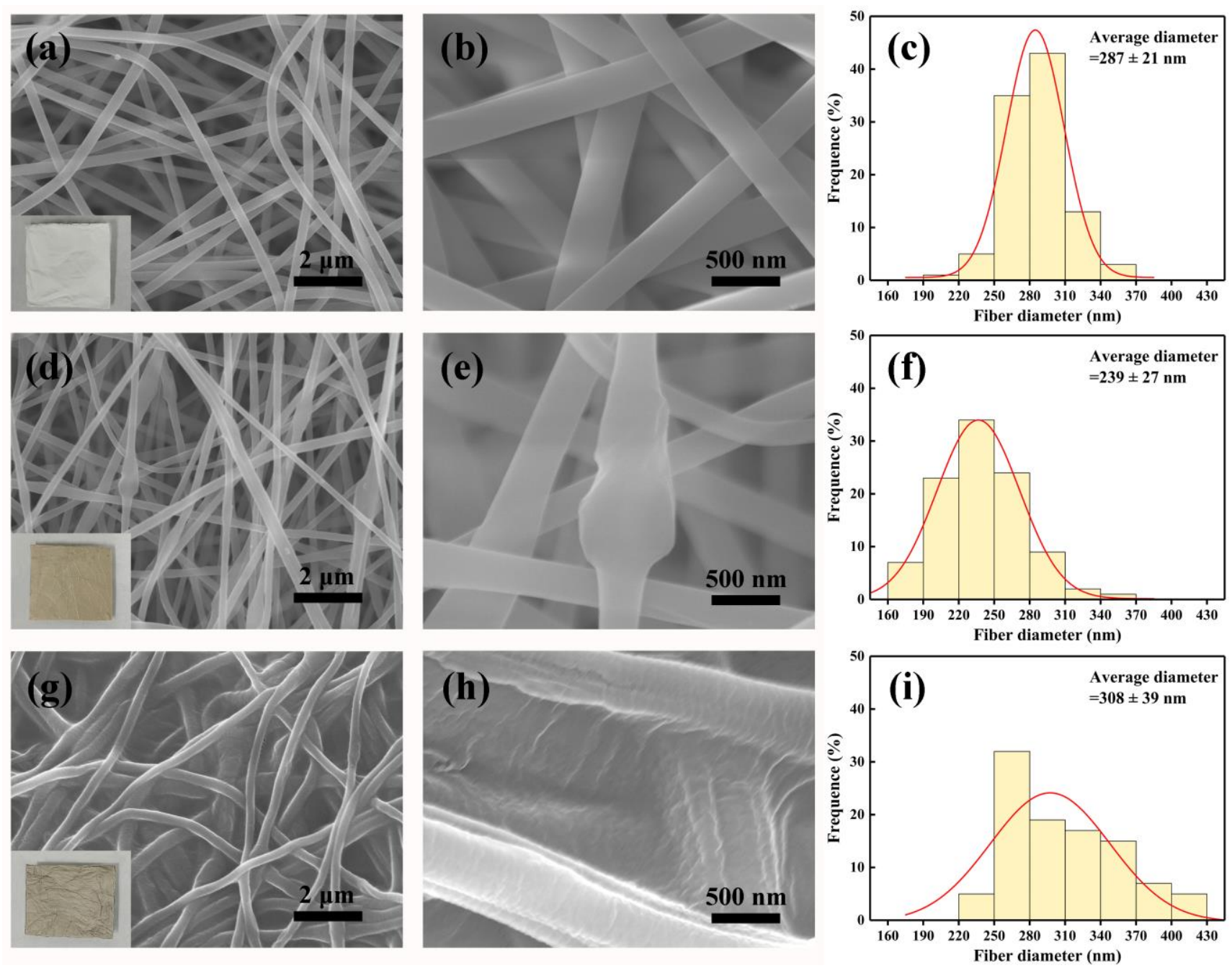

Fig. 2 SEM images and the diameter distribution of the membranes. (a-c) PAN, (d-f) GO/PAN and (g-i) CS-

GO/PAN (The illustrations were digital images of the membranes)

The chemical structure of nanofiber membranes was analyzed by FT-IR. As shown in Fig. 3 a, the characteristic peak of PAN representing stretching vibration of nitrile groups $(\mathrm{C} \equiv \mathrm{N})$ was observed at $2240 \mathrm{~cm}^{-1}$ and distinctive peaks at 2932 and $1450 \mathrm{~cm}^{-1}$ were the asymmetrical and symmetrical bending of $\mathrm{C}-\mathrm{H}$, respectively ${ }^{[33]}$. In addition, the peak around $1732 \mathrm{~cm}^{-1}$ was a typical peak formed by the stretching vibration of the $\mathrm{C}=\mathrm{O}$, the peak at $1047 \mathrm{~cm}^{-1}$ and $880 \mathrm{~cm}^{-1}$ were responsive to the $\mathrm{C}$ $\mathrm{O}$, and the peak at $3413 \mathrm{~cm}^{-1}$ was related to the stretching vibration of hydroxyl $(-\mathrm{OH})^{[34-36]}$. Various active groups, such as hydroxyl and carboxyl, were proved to be forming on the surface of GO/PAN after hydrolysis, which provided the basis for grafting reaction. The peaks at $2885 \mathrm{~cm}^{-1}\left(-\mathrm{CH}_{2}\right), 1339$ $\mathrm{cm}^{-1}$ (amine I C-N), $1150 \mathrm{~cm}^{-1}(\mathrm{C}-\mathrm{O}), 1103 \mathrm{~cm}^{-1}(\mathrm{C}-\mathrm{O}-\mathrm{C})$, and $959 \mathrm{~cm}^{-1}(\mathrm{C}-\mathrm{N})$ were assigned to the characteristic of the CS in Fig. $3 \mathrm{~b}^{[37]}$. The new stretching vibrations of amide $\mathrm{I} \mathrm{C}=\mathrm{O}\left(1670 \mathrm{~cm}^{-1}\right)$ and the bending vibrations of amide II N-H $\left(1579 \mathrm{~cm}^{-1}\right)$ indicated that amide bonds (-NHCO-) formed on 
the treated GO/PAN membrane surface ${ }^{[38]}$. The above results revealed that CS was successfully grafted onto the surface of GO/PAN membrane.
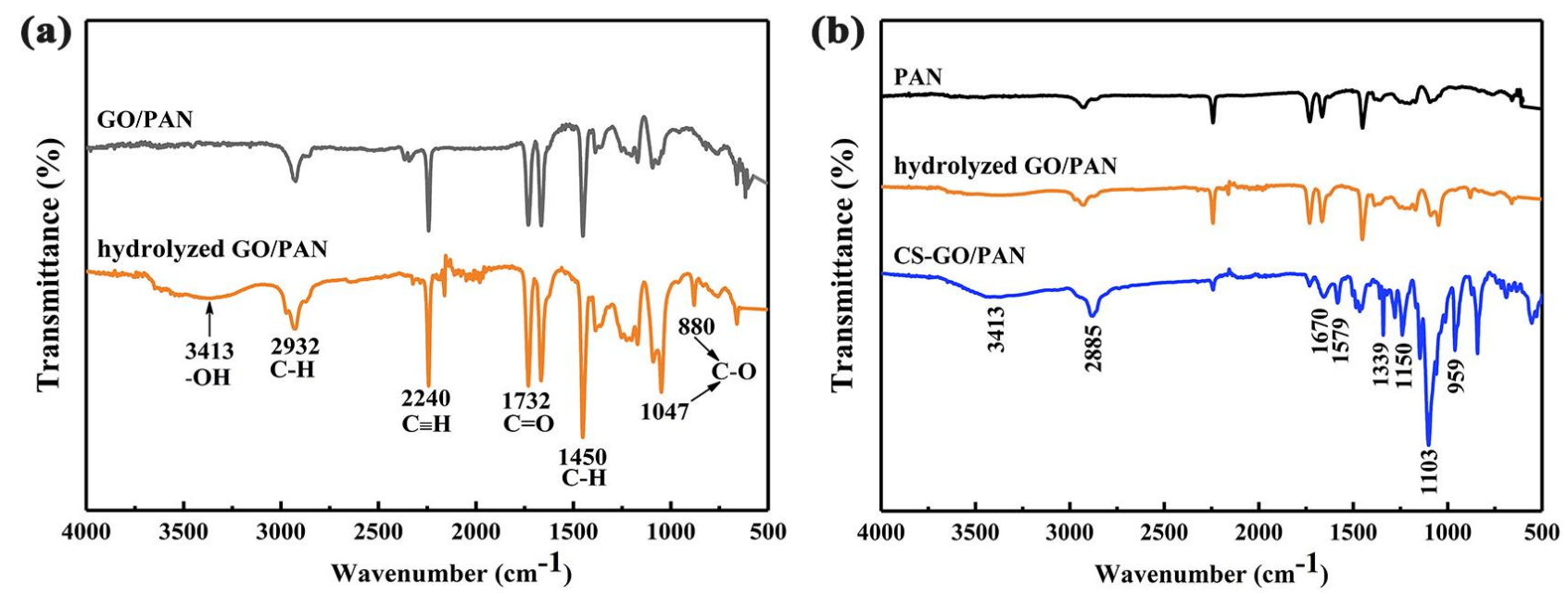

Fig. 3 Comparison of FT-IR patterns of (a) GO/PAN before and after hydrolysis and (b) PAN, hydrolyzed GO/PAN and $0.7 \mathrm{CS}-\mathrm{GO} / \mathrm{PAN}$

The EDX elemental analysis results of PAN, GO/PAN and 0.7CS-GO/PAN were shown in Fig. 4. The main elements in the three samples were carbon, nitrogen and oxygen. The increase of nitrogen and oxygen content in GO/PAN and $0.7 \mathrm{CS}-\mathrm{GO} / \mathrm{PAN}$ was attributed to the effect of active oxygen groups in GO and CS. EDX spectra confirmed that GO and CS were completely mixed in PAN.

(a)

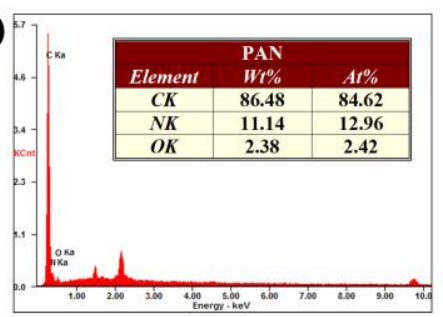

(b)

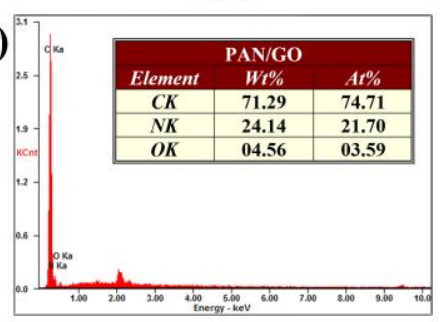

(c)

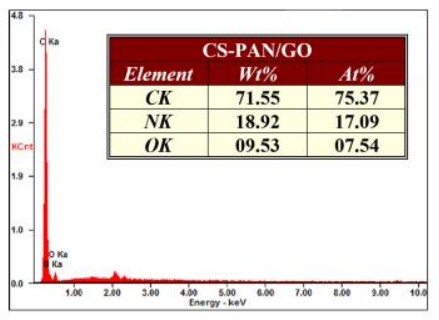

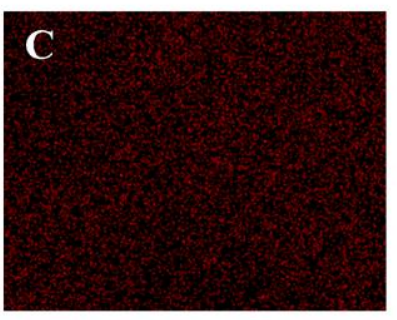
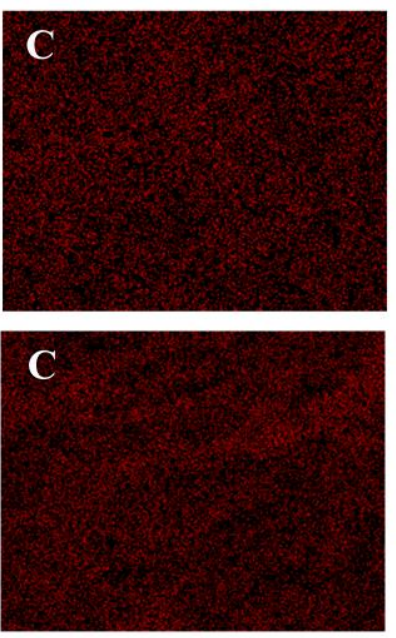
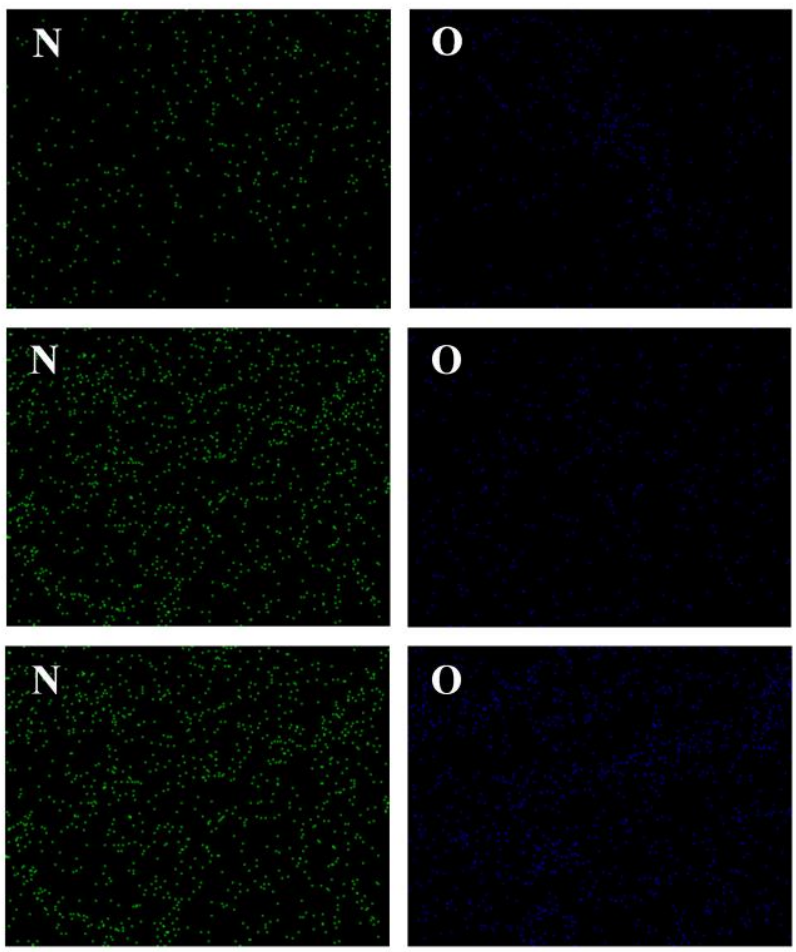
Fig. 4 EDX analysis of nanofiber membranes. (a) PAN, (b) GO/PAN and (c) 0.7 CS-GO/PAN

The permeability and selectivity of the membrane were influenced by the hydrophilicity of its surface. The improvement of hydrophilicity was beneficial to the penetration and adsorption of dyes $[39,40]$. The WCA results of the three types of membranes are shown in the Fig. 5. As a hydrophobic polymer, the initial WCA of the electrospun PAN membrane was about $131.4^{\circ}$ and only decreased by $1.5^{\circ}$ after $20 \mathrm{~s}$. The initial WCA of GO/PAN $\left(115.5^{\circ}\right)$ after mixing GO was smaller than PAN, and there is a certain degree of decrease $\left(4.9^{\circ}\right)$ after 20 s. However, it still showed hydrophobicity. The membrane was proved to improved hydrophilicity after grafting CS. The initial WCA of 0.7CS$\mathrm{GO} / \mathrm{PAN}$ is $24.5^{\circ}$ and the water-drop penetrated the membrane in a very short time $(<0.5 \mathrm{~s})$, showing super hydrophilicity.

\begin{tabular}{|c|c|c|c|c|c|c|c|c|}
\hline & $0 \mathrm{~s}$ & $0.1 \mathrm{~s}$ & $0.5 \mathrm{~s}$ & $1 \mathrm{~s}$ & $2 \mathrm{~s}$ & $5 \mathrm{~s}$ & $10 \mathrm{~s}$ & $20 \mathrm{~s}$ \\
\hline & $\mathrm{CA}=131.4^{\circ}$ & $\mathrm{CA}=131.3^{\circ}$ & $\mathrm{CA}=131.1^{\circ}$ & $\mathrm{CA}=131.0^{\circ}$ & $\mathrm{CA}=130.8^{\circ}$ & $\mathrm{CA}=130.7^{\circ}$ & $\mathrm{CA}=130.1^{\circ}$ & $\mathrm{CA}=129.9^{\circ}$ \\
\hline GO/PAN & $\mathrm{CA}=115.5^{\circ}$ & $\mathrm{CA}=115.3^{\circ}$ & $\mathrm{CA}=114.6^{\circ}$ & $\mathrm{CA}=113.7^{\circ}$ & $\mathrm{CA}=113.1^{\circ}$ & $\mathrm{CA}=112.2^{\circ}$ & $\mathrm{CA}=111.5^{\circ}$ & $\mathrm{CA}=110.6^{\circ}$ \\
\hline 0.7CS-GO/PAN & $\mathrm{CA}=24.5^{\circ}$ & $\mathrm{CA}=18.7^{\circ}$ & $\mathrm{CA}=0^{\circ}$ & $\mathrm{CA}=0^{\circ}$ & $\mathrm{CA}=0^{\circ}$ & $\mathrm{CA}=0^{\circ}$ & $\mathrm{CA}=0^{\circ}$ & $\mathbf{C A}=\mathbf{0}^{\circ}$ \\
\hline
\end{tabular}

Fig. 5 Contact angle of PAN, GO/PAN and 0.7CS-GO/PAN nanofiber membranes

\section{Adsorption activity of CS-GO/PAN nanofiber membranes}

\section{Effect of membrane types}

Different types of the membrane were selected to remove SY in order to investigate the best ratio of GO and $\mathrm{CS}$. The introduction of GO was demonstrated to increase the adsorption efficiency by $23 \%$. The adsorption efficiency increased significantly with the increase of CS addition (Fig. 6 a). 0.7CSGO/PAN has been observed the highest adsorption efficiency, which was 90 times that of PAN Therefore, the adsorption capacity and adsorption mechanism of SY by $0.7 \mathrm{CS}-\mathrm{GO} / \mathrm{PAN}$ nanofiber membrane (Hereafter referred to as CS-GO/PAN) was investigated in detail. 

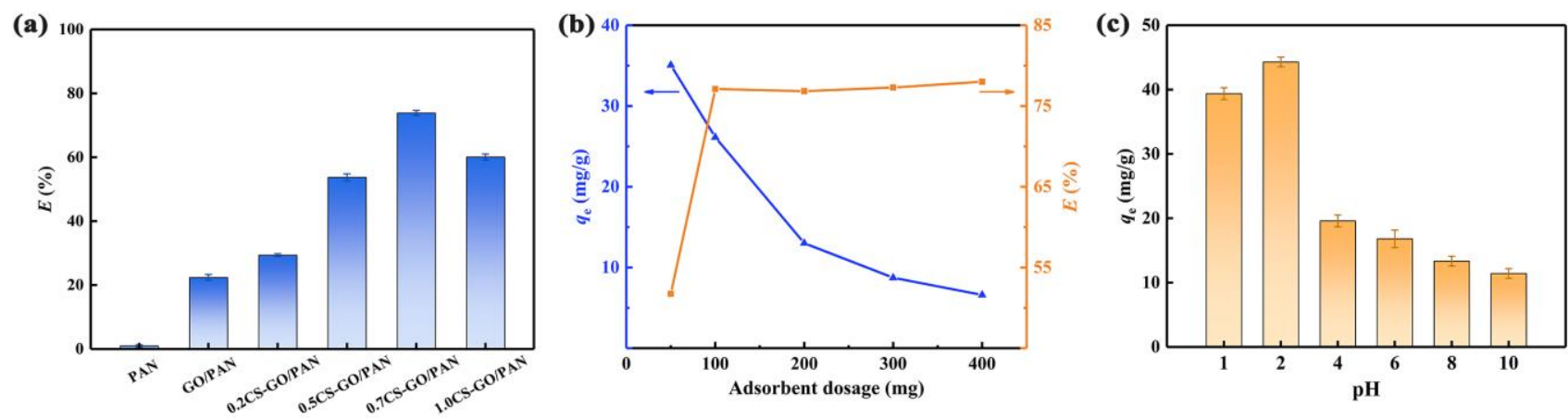

Fig. 6 Effect of membrane type (a), the dosage (b) and $\mathrm{pH}$ of solution (c) on the absorption of SY onto the nanofiber membranes

\section{Effect of CS-GO/PAN membrane dosage}

The adsorption efficiency and adsorption capacity of CS-GO/PAN in the range of 50 to $400 \mathrm{mg}$ for SY are shown in Fig. 6 b. The adsorption efficiency ascended sharply from $51.74 \%$ to $77.12 \%$ with the increase of membrane mass from 50 to $100 \mathrm{mg}$. The ascending trend was related to the increase of the active sites and surface area of the membrane. However, the further increase did not significantly change the adsorption efficiency when the dosage reached $100 \mathrm{mg}$, because surface saturation resulted in the unavailability of adsorption sites. It was also observed that the adsorption capacity descended from $35.07 \mathrm{mg} / \mathrm{g}$ to $6.61 \mathrm{mg} / \mathrm{g}$ with the ascend of dosage from $50 \mathrm{mg}$ to $400 \mathrm{mg}$, because fewer dye molecules were exposed to a unit mass of CS-GO/PAN, and active sites could not be covered completely. The optimum dosage of $100 \mathrm{mg}$ was utilized in the subsequent experiments to reduce errors and further explore the adsorption mechanism.

\section{Effect of $\mathrm{pH}$ value}

The $\mathrm{pH}$ is an important factor of the adsorption process as it affects the ionization degree of the adsorbent and the speciation of various dyes ${ }^{[41]}$. A wide range of $\mathrm{pH}$ was used in the experiment. CSGO/PAN had better adsorption for SY under acidic conditions from Fig. 6 c. The adsorption capacity reached the maximum value of $44.29 \mathrm{mg} / \mathrm{g}$ at $\mathrm{pH} 2$. There were massive protons in the acidic solution, thus the amino and hydroxyl groups in the membrane were protonated, leading to the surface with positive charges. The negative charges in the anionic dye SY combined with the positive charges on the surface of the membrane by electrostatic attraction, promoting the adsorption for SY. Therefore, the following experiments were conducted using the solution at $\mathrm{pH} 2$. 


\section{Adsorption Kinetic}

The residual SY concentration was measured at a different time to explain the adsorption kinetic mechanism. Two different initial concentrations of SY were used for comparison. As shown in Fig. 7 a, the adsorption capacity of CS-GO/PAN increased rapidly in $0-60 \mathrm{~min}$, and $80 \%$ of SY was removed in $15 \mathrm{~min}$, while increased slowly within 60-240 min, and then gradually stabilized. SY was almost completely removed finally. Adequate binding sites and positive charges were exposed on the surface of the membrane in the initial stage of adsorption, offering an enhanced adsorption rate. With the extension of time, the sites tended to be saturated and the positive charges reduced, weakening the adsorption. Besides, the absorption spectrum of $100 \mathrm{mg} / \mathrm{L} \mathrm{SY}$ was measured at the corresponding time (Fig. 7 b). The characteristic peak of SY was observed to decrease drastically in 15 min and then remained approximately unchanged in $240 \mathrm{~min}$. In order to ensure that SY was adsorbed fully by CS$\mathrm{GO} / \mathrm{PAN}$ and save experimental time, the adsorption time was determined to be $240 \mathrm{~min}$.
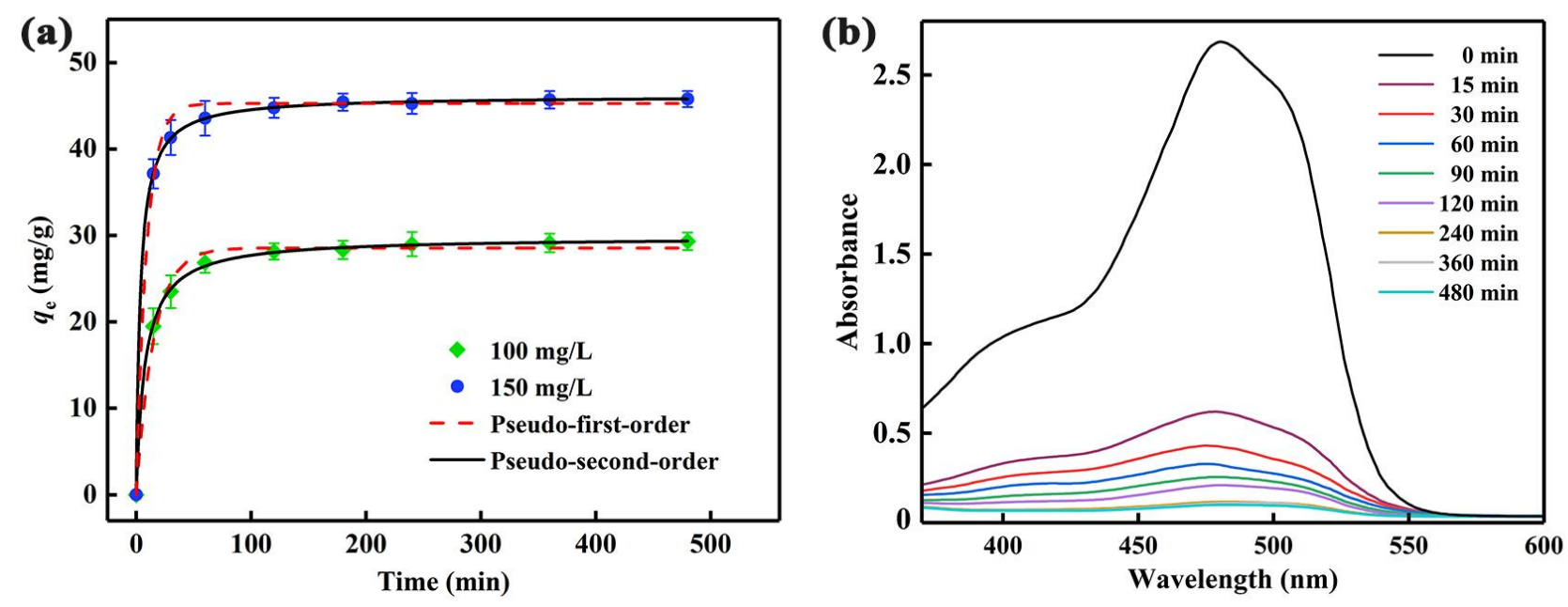

Fig. 7 Effect of contact time for (a) SY adsorption and kinetic fitting on CS-GO/PAN and (b) UV-vis spectra of SY solution

To get further determine the adsorption process of dyes on CS-GO/PAN, the kinetic data were fitted with the pseudo-first-order kinetic model (Eq. 4) and pseudo-second-order kinetic model (Eq. 5). The pseudo-first-order kinetic model is based on the approximation that the adsorption rate relates to the number of the unoccupied adsorptive sites and one adsorbate is adsorbed onto one site. Whereas, the pseudo-second-order kinetic model assumes that adsorption relates to the squared product of the difference between the number of the available equilibrium sites and the occupied sites ${ }^{[27]}$. The forms 
of the two models could be described in the following equations ${ }^{[42]}$ :

$\ln \left(q_{e}-q_{t}\right)=\ln q_{e}-k_{1} t$

$t / q_{t}=t / q_{e}+1 /\left(k_{2} q_{e}^{2}\right)$

Where $q_{e}(\mathrm{mg} / \mathrm{g})$ is the adsorption capacity at equilibrium, $q_{t}(\mathrm{mg} / \mathrm{g})$ is the amount of adsorbed $\mathrm{SY}$ on the CS-GO/PAN at time $t(\mathrm{~min}) . k_{1}\left(\mathrm{~min}^{-1}\right)$ and $k_{2}(\mathrm{~g} /(\mathrm{mg} \cdot \mathrm{min}))$ are the rate constant of pseudofirst-order kinetic equation and pseudo second-order kinetic equation, respectively.

The kinetic model type of adsorption process could be used to identify the rate-controlling mechanisms by the correlation coefficient $\left(\mathrm{R}^{2}\right)$. The kinetic parameters and $\mathrm{R}^{2}$ were summarized in Table 3. The $\mathrm{R}^{2}$ of the pseudo-second-order model ( 0.998 and 0.999 , respectively) were higher than the pseudo-first-order model ( 0.983 and 0.987 , respectively) at the two concentrations, which was proved that the adsorption data of CS-GO/PAN was fitted the pseudo-second-order model better.

Table 3 Pseudo-first and second-order kinetic parameters for SY absorption on CS-GO/PAN using two initial dye concentrations

\begin{tabular}{|c|c|c|c|c|c|c|c|}
\hline \multirow{2}{*}{$\begin{array}{c}\mathrm{SY} \\
(\mathrm{mg} / \mathrm{L})\end{array}$} & \multirow{2}{*}{$\begin{array}{l}q_{e}, \exp \\
(\mathrm{mg} / \mathrm{g})\end{array}$} & \multicolumn{3}{|c|}{ Pseudo-first order model } & \multicolumn{3}{|c|}{ Pseudo-second order model } \\
\hline & & $\begin{array}{l}q_{e}, \mathrm{cal} \\
(\mathrm{mg} / \mathrm{g})\end{array}$ & $\begin{array}{c}k_{1} \\
\left(\min ^{-1}\right)\end{array}$ & $R^{2}$ & $\begin{array}{l}q_{e}, \mathrm{cal} \\
(\mathrm{mg} / \mathrm{g})\end{array}$ & $\begin{array}{c}k_{2} \\
(\mathrm{~g} /(\mathrm{mg} \cdot \min ))\end{array}$ & $R^{2}$ \\
\hline 100 & 29.31 & 28.55 & 0.065 & 0.983 & 29.81 & 0.004 & 0.998 \\
\hline 150 & 45.78 & 45.27 & 0.109 & 0.987 & 46.15 & 0.006 & 0.999 \\
\hline
\end{tabular}

Adsorption Isotherm

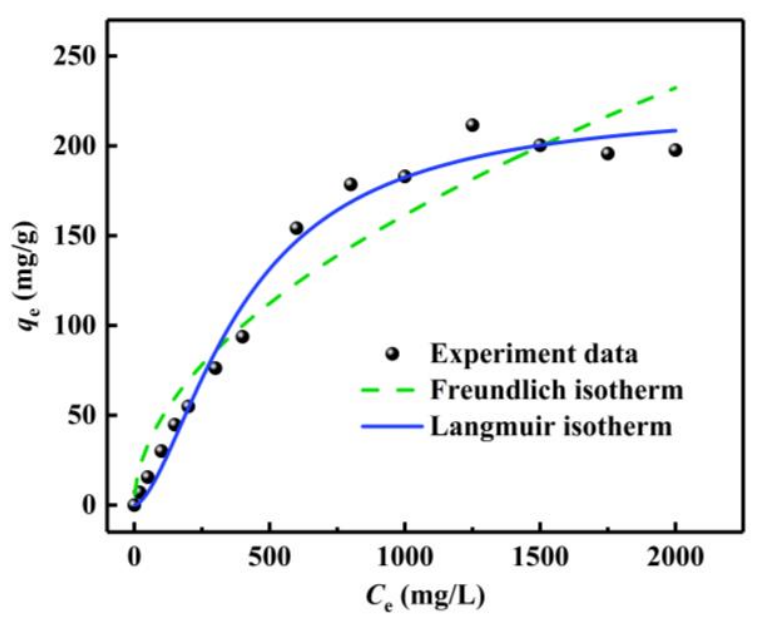

Fig. 8 Adsorption isotherms and fitting for SY on CS-GO/PAN

The adsorption isotherm is the relation curve between the adsorption capacity and concentration of solution when the adsorption reaches equilibrium. As presented in Fig. 8, the adsorption curve risen 
with the increase of the initial concentration and then decreased slightly. The maximum adsorption capacity $\left(q_{\max }\right)$ of CS-GO/PAN was $211.54 \mathrm{mg} / \mathrm{g}$ at $1250 \mathrm{mg} / \mathrm{L}$. Langmuir and Freundlich models were utilized to interpret the isotherm adsorption data for further analyze the interaction between CSGO/PAN and SY. Langmuir model presents monolayer adsorption based on the assumption of adsorption uniformity, while Freundlich model is an empirical description for adsorption equilibrium of a single component ${ }^{[43]}$. The linear equations of two isotherm models were respectively expressed as follows:

$$
\begin{aligned}
& c_{e} / q_{e}=c_{e} / q_{\max }+1 /\left(K_{L} q_{\max }\right) \\
& \ln q_{e}=(1 / n) \ln c_{e}+\ln K_{F}
\end{aligned}
$$

where $q_{\max }(\mathrm{mg} / \mathrm{g})$ is the Langmuir maximum adsorption capacity. $K_{\mathrm{L}}(\mathrm{L} / \mathrm{mg})$ and $K_{\mathrm{F}}((\mathrm{mg} / \mathrm{g})$ $\left.(\mathrm{L} / \mathrm{mg})^{1 / \mathrm{n}}\right)$ are the rate constant of Langmuir model and Freundlich model, respectively. $n$ is Freundlich heterogeneity factor related to the heat of adsorption.

Table 4 Langmuir and Freundlich model parameters for SY adsorption on CS-GO/PAN

\begin{tabular}{cccccccc}
\hline \multicolumn{3}{c}{ Langmuir model } & & \multicolumn{3}{c}{ Freundlich model } \\
\cline { 1 - 2 } \cline { 6 - 7 }$q_{\max }(\mathrm{mg} / \mathrm{g})$ & $K_{\mathrm{L}(\mathrm{L} / \mathrm{mg})}$ & $R^{2}$ & & $n$ & $K_{\mathrm{F}}\left((\mathrm{mg} / \mathrm{g})(\mathrm{L} / \mathrm{mg})^{1 / \mathrm{n}}\right)$ & $R^{2}$ \\
\hline 223.68 & 0.005 & 0.980 & & 4.33 & 1.908 & 0.923 \\
\hline
\end{tabular}

The parameters in Table 4 reveal that the experimental data were well fitted with the Langmuir model $\left(\mathrm{R}^{2}=0.980\right)$ instead of the Freundlich model $\left(\mathrm{R}^{2}=0.923\right)$. This implied that the adsorption behavior of on CS-GO/PAN for SY belongs to Langmuir model, that is, adsorption of a mono molecular layer for SY and uniform distribution of active centers on the fiber surface. The $q_{\max }$ of CS$\mathrm{GO} / \mathrm{PAN}$ was $223.68 \mathrm{mg} / \mathrm{g}$ according to the Langmuir fitting parameter, which was very close to the actual results $(211.54 \mathrm{mg} / \mathrm{g})$.

\section{Regenerability of Membrane}

The excellent reusability of adsorbent is conducive to reducing usage costs. The positively charged groups on the adsorbent are deprotonated in the concentrated alkaline solution leading to adsorbed SY shed from the membrane. Therefore, the used membrane should be regenerated in an alkaline solution, as reported in previous literature ${ }^{[44]}$. The data of the desorption experiment implied that $1 \mathrm{M} \mathrm{NaOH}$ solution had a fast and terrific desorption effect for SY adsorbed on the surface of CSGO/PAN, 77.8\% of SY being separated in 5 min (Fig. 9 a). Although the adsorption capacity and 
desorption capacity slightly decreased after five-time regeneration, they still reached $90 \%$ and $93 \%$, respectively. Besides, the average desorption capacity of five cycles was over $95 \%$, which realized the complete desorption of SY basically (Fig. 9 b). The results above demonstrated high reusability and excellent regeneration property of CS-GO/PAN.
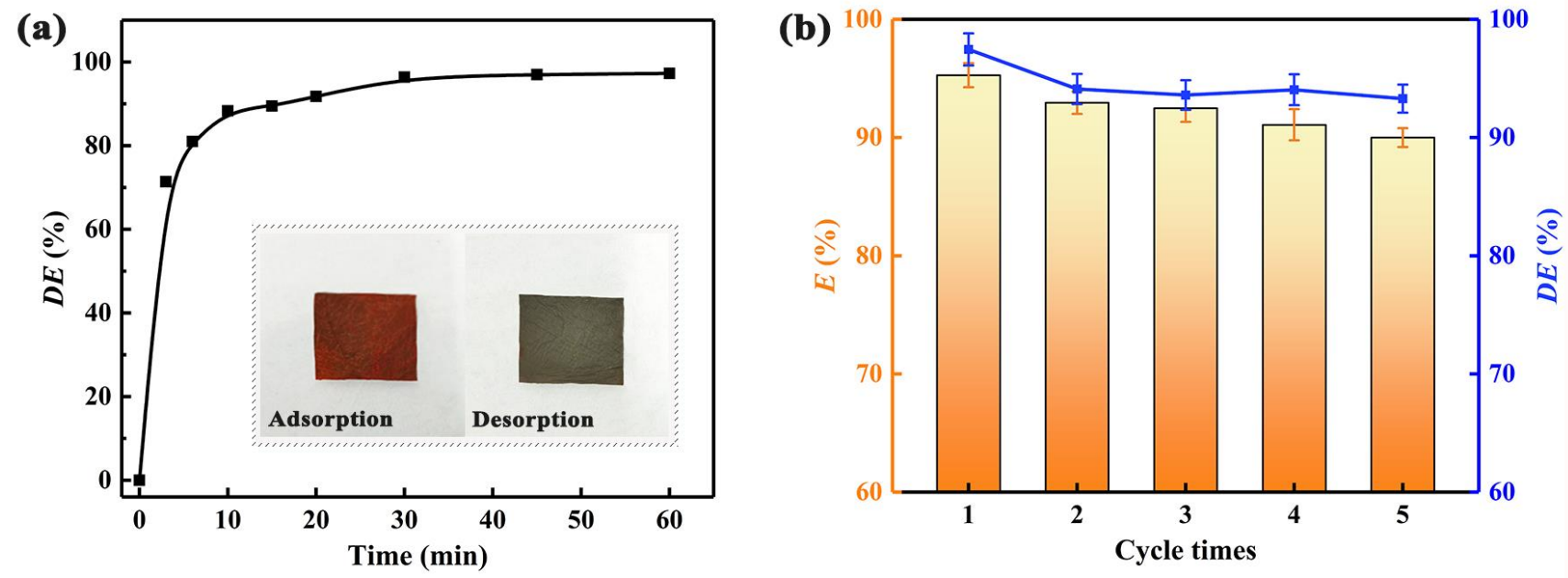

Fig. 9 Desorption efficiency (a) and regeneration (b) of CS-GO/PAN nanofiber membrane for SY in adsorptiondesorption cycles (The illustrations were digital images of CS-GO/PAN in cycles)

The $q_{\text {max }}$ of CS-GO/PAN for SY with that of other reported adsorbents was compared in Table 5. It could be seen that $q_{\max }$ of CS-GO/PAN belonged to a high level, while most adsorbents were less than $200 \mathrm{mg} / \mathrm{g}$. A few adsorbents with high $q_{\max }$ showed high preparation costs, complex synthesis processes, or long adsorption time. In contrast, CS-GO/PAN was prepared by a simple and low-cost method using a hot water bath. Most raw materials were cheap and easy to obtain, while only expensive GO had little dosage. The adsorption process was also speedy and convenient. More importantly, CSGO/PAN still maintained original morphology in reuse (Digital images in Fig. 9 a), thus the membrane could be recovered easily by taking out the membrane or draining the wastewater.

Table 5 Comparison of adsorption capacities with various reported adsorbents for SY

\begin{tabular}{|c|c|c|c|c|}
\hline Absorbents & $\mathrm{pH}$ & Equilibrium time (min) & $q_{\max }(\mathrm{mg} / \mathrm{g})$ & Reference \\
\hline MOFs/GO & 9 & 60 & 81.28 & {$[45]$} \\
\hline $\mathrm{Cu} / \mathrm{C}-\mathrm{MA}$ & 2 & 200 & 105.00 & [46] \\
\hline OMC-2Nd & 2.5 & 240 & 285.71 & [47] \\
\hline TRGO & 6 & 150 & 243.3 & [48] \\
\hline $\mathrm{Ch}-\mathrm{V}$ & 9.6 & 1440 & 175.1 & [49] \\
\hline $\mathrm{Ni}-\mathrm{Ag} \mathrm{NPs} / \mathrm{rGO}$ & 3 & 15 & 28.57 & [50] \\
\hline PILPyr $^{+}$AA-TFSI ${ }^{-}$ & 10 & 1440 & 316.5 & [51] \\
\hline
\end{tabular}




\begin{tabular}{ccccc}
$\mathrm{Fe}^{3+}$-TA-HCHO & 2 & 240 & 30 & [52] \\
CS-GO/PAN & 2 & 240 & 211.54 & This work \\
\hline
\end{tabular}

\section{Conclusion}

CS-GO/PAN nanofiber membranes were prepared by electrospinning and grafting reaction. It was observed that CS-GO/PAN was porous, while GO was wrapped in the fibers, and CS was covered on the membrane. The existence of active groups for adsorption was determined and GO and CS were completely mixed in PAN. It also confirmed the excellent hydrophilicity of CS-GO/PAN. The adsorption capacity of CS-GO/PAN for SY was $211.54 \mathrm{mg} / \mathrm{g}$ at $\mathrm{pH} 2$, and over $80 \%$ of SY could be adsorbed in $15 \mathrm{~min}$. The adsorption kinetics and isotherm obeyed pseudo-second-order model and Langmuir model, respectively. In addition, adsorbed SY on CS-GO/PAN was separated rapidly in $\mathrm{NaOH}$ solution. Adsorption capacity and membrane integrity were effectively maintained after 5 regeneration cycles. In general, $\mathrm{CS}-\mathrm{GO} / \mathrm{PAN}$ membrane would be considered as a promising adsorbent for dye removal from industrial wastewater.

\section{Declarations}

Funding Open Access funding provided by Tiangong University.

Competing interests The authors declare that they have no competing interests.

Availability of data and material Not applicable' for this section.

Code availability Not applicable' for this section.

Authors' contributions YL-designed and conducted the experiment, collected data, formal analysis and wrote the manuscript; WZ-designed the experiment, corrected and revised the manuscript; HZread and revised the manuscript; JL-designed the experiment; MW-material preparation.

Ethics approval Not applicable' for that section.

Consent to participate Not applicable' for that section.

Consent for publication Not applicable' for that section.

Acknowledgments This work was supported by National College Student Innovation and Entrepreneurship Training Program (201810058053) and Tianjin Municipal College Students Innovation and Entrepreneurship Training Program (202010058042). We would like to thank the Analytical \& Testing Center of Tiangong University for providing characterization facilities. 


\section{References}

1. Ahmad A, Mohd-Setapar SH, Chuong CS, Khatoon A, Wani WA, Kumar R, Rafatullah M (2015) Recent advances in new generation dye removal technologies: novel search for approaches to reprocess wastewater. Rsc Adv 5: 3080130818.https://doi.org/10.1039/c4ra16959j

2. Piaskowski K, Swiderska-Dabrowska R, Zarzycki PK (2018) Dye Removal from Water and Wastewater Using Various Physical, Chemical, and Biological Processes. J Aoac Int 101: 13711384.https://doi.org/10.5740/jaoacint.18-0051

3. Katheresan V, Kansedo J, Lau SY (2018) Efficiency of various recent wastewater dye removal methods: A review. Journal of Environmental Chemical Engineering 6: 46764697.https://doi.org/10.1016/i.jece.2018.06.060

4. Chaibakhsh N, Ahmadi N, Zanjanchi MA (2014) Use of Plantago major L. as a natural coagulant for optimized decolorization of dye-containing wastewater. Ind Crop Prod 61: 169175.https://doi.org/10.1016/j.indcrop.2014.06.056

5. Yavuz Y, Shahbazi R, Koparal AS, Ogutveren UB (2014) Treatment of Basic Red 29 dye solution using iron-aluminum electrode pairs by electrocoagulation and electro-Fenton methods. Environ Sci Pollut R 21: 8603-8609.https://doi.org/10.1007/s11356-014-2789-8

6. Rejek M, Grzechulska-Damszel J, Schmidt B (2021) Synthesis, Characterization, and Evaluation of Degussa P25/Chitosan Composites for the Photocatalytic Removal of Sertraline and Acid Red 18 from Water. J Polym Environ.https://doi.org/10.1007/s10924-021-02138-x

7. Hang G, Feng YN, Chung TS, Weber M, Maletzko C (2017) Phase Inversion Directly Induced Tight Ultrafiltration (UF) Hollow Fiber Membranes for Effective Removal of Textile Dyes. Environ Sci Technol 51: 14254-14261.https://doi.org/10.1021/acs.est.7b05340

8. Liu WJ, Liu L, Liu C, Hao Y, Yang H, Yuan B, Jiang JH (2016) Methylene blue enhances the anaerobic decolorization and detoxication of azo dye by Shewanella onediensis MR-1. Biochem Eng J 110: 115-124.https://doi.org/10.1016/j.bej.2016.02.012

9. Nakhjiri MT, Marandi GB, Kurdtabar M (2019) Adsorption of Methylene Blue, Brilliant Green and Rhodamine B from Aqueous Solution Using Collagen-g-p(AA-co-NVP)/Fe3O4@SiO2 Nanocomposite Hydrogel. J Polym Environ 27: 581-599.https://doi.org/10.1007/s10924-019$\underline{01372-8}$

10. Crini G, Lichtfouse E, Wilson LD, Morin-Crini N (2019) Conventional and non-conventional adsorbents for wastewater treatment. Environ Chem Lett 17: 195213.https://doi.org/10.1007/s10311-018-0786-8

11. Zhou YB, Lu J, Zhou Y, Liu YD (2019) Recent advances for dyes removal using novel adsorbents: A review. Environ Pollut 252: 365.https://doi.org/10.1016/j.envpol.2019.05.072

12. Yan H, Wu H, Li K, Wang YW, Tao X, Yang H, Li AM, Cheng RS (2015) Influence of the Surface Structure of Graphene Oxide on the Adsorption of Aromatic Organic Compounds from Water. Acs Appl Mater Inter 7: 6690-6697.https://doi.org/10.1021/acsami.5b00053

13. Chen D, Feng HB, Li JH (2012) Graphene Oxide: Preparation, Functionalization, and Electrochemical Applications. Chem Rev 112: 6027-6053.https://doi.org/10.1021/cr300115g 
14. Thakur K, Kandasubramanian B (2019) Graphene and Graphene Oxide-Based Composites for Removal of Organic Pollutants: A Review. J Chem Eng Data 64: 833867.https://doi.org/10.1021/acs.jced.8b01057

15. Abd-Elhamid AI, Kamoun EA, El-Shanshory AA, Soliman HMA, Aly HF (2019) Evaluation of graphene oxide-activated carbon as effective composite adsorbent toward the removal of cationic dyes: Composite preparation, characterization and adsorption parameters. J Mol Liq 279: 530-539.https://doi.org/10.1016/j.molliq.2019.01.162

16. Jiao CL, Li TT, Wang J, Wang H, Zhang XL, Han XJ, Du ZF, Shang YL, Chen YY (2020) Efficient Removal of Dyes from Aqueous Solution by a Porous Sodium Alginate/gelatin/graphene Oxide Triple-network Composite Aerogel. J Polym Environ 28: 1492-1502.https://doi.org/10.1007/s10924-020-01702-1

17. Xing JS, Wang XJ, Xun JJ, Peng J, Xu Q, Zhang WX, Lou T (2018) Preparation of micronanofibrous chitosan sponges with ternary solvents for dye adsorption. Carbohyd Polym 198: 69-75.https://doi.org/10.1016/j.carbpol.2018.06.064

18. Zhang DX, Xiao JF, Guo QQ, Yang J (2019) 3D-printed highly porous and reusable chitosan monoliths for $\mathrm{Cu}(\mathrm{II})$ removal. J. Mater. Sci. 54: 6728-6741.https://doi.org/10.1007/s10853$\underline{019-03332-y}$

19. Zheng XJ, Li XX, Li JY, Wang LW, Jin WJ, Liu J, Pei Y, Tang KY (2018) Efficient removal of anionic dye (Congo red) by dialdehyde microfibrillated cellulose/chitosan composite film with significantly improved stability in dye solution. International Journal of Biological Macromolecules 107: 283-289.https://doi.org/10.1016/j.ijbiomac.2017.08.169

20. Jiang Y, Gong JL, Zeng GM, Ou XM, Chang YN, Deng CH, Zhang J, Liu HY, Huang SY (2016) Magnetic chitosan-graphene oxide composite for anti-microbial and dye removal applications. International Journal of Biological Macromolecules 82: 702710.https://doi.org/10.1016/j.ijbiomac.2015.11.021

21. Liao Y, Loh CH, Tian M, Wang R, Fane AG (2018) Progress in electrospun polymeric nanofibrous membranes for water treatment: Fabrication, modification and applications. Prog Polym Sci 77: 69-94.https://doi.org/10.1016/j.progpolymsci.2017.10.003

22. Jung JW, Lee CL, Yu S, Kim ID (2016) Electrospun nanofibers as a platform for advanced secondary batteries: a comprehensive review. J Mater Chem A 4: 703750.https://doi.org/10.1039/c5ta06844d

23. Thavasi V, Singh G, Ramakrishna S (2008) Electrospun nanofibers in energy and environmental applications. Energ Environ Sci 1: 205-221.https://doi.org/10.1039/b809074m

24. Yang Q, Guo XX, Ye XF, Zhu HJ, Kong LX, Hou TT (2020) Functionalized polyacrylonitrile fibers with durable antibacterial activity and superior $\mathrm{Cu}(\mathrm{II})$-removal performance. Materials Chemistry and Physics 245.https://doi.org/10.1016/j.matchemphys.2020.122755

25. Nataraj SK, Yang KS, Aminabhavi TM (2012) Polyacrylonitrile-based nanofibers A state-ofthe-art review. Prog Polym $\quad$ Sci $\quad 37$ : 513.https://doi.org/10.1016/j.progpolymsci.2011.07.001

26. Chen C, Li FL, Guo ZH, Qu XY, Wang JT, Zhang J (2019) Preparation and performance of aminated polyacrylonitrile nanofibers for highly efficient copper ion removal. Colloid Surface A 568: 334-344.https://doi.org/10.1016/j.colsurfa.2019.02.020 
27. Haider S, Binagag FF, Haider A, Al-Masry WA (2014) Electrospun oxime-graftedpolyacrylonitrile nanofiber membrane and its application to the adsorption of dyes. J Polym Res 21.https://doi.org/10.1007/s10965-014-0371-1

28. Yadav A, Kumar A, Tripathi A, Das M (2013) Sunset yellow FCF, a permitted food dye, alters functional responses of splenocytes at non-cytotoxic dose. Toxicol Lett 217: 197204.https://doi.org/10.1016/j.toxlet.2012.12.016

29. Mok CF, Ching YC, Muhamad F, Abu Osman NA, Hai ND, Hassan CRC (2020) Adsorption of Dyes Using Poly(vinyl alcohol) (PVA) and PVA-Based Polymer Composite Adsorbents: A Review. J Polym Environ 28: 775-793.https://doi.org/10.1007/s10924-020-01656-4

30. Li JH, Zhang H, Zhang W, Liu WL (2019) Nanofiber membrane of graphene oxide/polyacrylonitrile with highly efficient antibacterial activity. J Biomat Sci-Polym E 30: 1620-1635.https://doi.org/10.1080/09205063.2019.1652793

31. Naseeb N, Mohammed AA, Laoui T, Khan Z (2019) A Novel PAN-GO-SiO2 Hybrid Membrane for Separating Oil and Water from Emulsified Mixture. Materials 12.https://doi.org/10.3390/ma12020212

32. Wong TS, Ho CM (2009) Dependence of Macroscopic Wetting on Nanoscopic Surface Textures. Langmuir 25: 12851-12854.https://doi.org/10.1021/la902430w

33. Lalia BS, Kochkodan V, Hashaikeh R, Hilal N (2013) A review on membrane fabrication: Structure, properties and performance relationship. Desalination 326: 77 95.https://doi.org/10.1016/j.desal.2013.06.016

34. Zhao RH, Tian MW, Qu LJ, Zhao YL, Chen SJ, Zhu SF, Han GT (2019) Wet-spinning assembly of continuous and macroscopic graphene oxide/polyacrylonitrile reinforced composite fibers with enhanced mechanical properties and thermal stability. J Appl Polym Sci 136.https://doi.org/10.1002/app.46950

35. Singh RK, Kumar R, Singh DP (2016) Graphene oxide: strategies for synthesis, reduction and frontier applications. Rsc Adv 6: 64993-65011.https://doi.org/10.1039/c6ra07626b

36. Pei SF, Wei QW, Huang K, Cheng HM, Ren WC (2018) Green synthesis of graphene oxide by seconds timescale water electrolytic oxidation. Nat Commun 9.https://doi.org/10.1038/s41467$\underline{017-02479-z}$

37. Xu WR, Xie WJ, Huang XQ, Chen X, Huang N, Wang X, Liu J (2017) The graphene oxide and chitosan biopolymer loads $\mathrm{TiO} 2$ for antibacterial and preservative research. Food Chem 221: 267-277.https://doi.org/10.1016/j.foodchem.2016.10.054

38. Cao WB, Yue L, Wang ZP (2019) High antibacterial activity of chitosan - molybdenum disulfide nanocomposite. Carbohyd Polym 215: 226234.https://doi.org/10.1016/j.carbpol.2019.03.085

39. Babu J, Murthy ZVP (2017) Treatment of textile dyes containing wastewaters with PES/PVA thin film composite nanofiltration membranes. Sep Purif Technol 183: 6672.https://doi.org/10.1016/j.seppur.2017.04.002

40. Nikooe N, Saljoughi E (2017) Preparation and characterization of novel PVDF nanofiltration membranes with hydrophilic property for filtration of dye aqueous solution. Appl Surf Sci 413: 41-49.https://doi.org/10.1016/j.apsusc.2017.04.029

41. Carpio IEM, Mangadlao JD, Nguyen HN, Advincula RC, Rodrigues DF (2014) Graphene 
oxide functionalized with ethylenediamine triacetic acid for heavy metal adsorption and antimicrobial applications. Carbon 77: 289-301.https://doi.org/10.1016/j.carbon.2014.05.032

42. Stanly S, Jelmy EJ, John H (2020) Studies on Modified Montmorillonite Clay and Its PVA Nanohybrid for Water Purification. J Polym Environ 28: 24332443.https://doi.org/10.1007/s10924-020-01786-9

43. Zhao WF, Tang YS, Xi J, Kong J (2015) Functionalized graphene sheets with poly(ionic liquid)s and high adsorption capacity of anionic dyes. Appl Surf Sci 326: 276284.https://doi.org/10.1016/j.apsusc.2014.11.069

44. Sahnoun S, Boutahala M (2018) Adsorption removal of tartrazine by chitosan/polyaniline composite: Kinetics and equilibrium studies. International Journal of Biological Macromolecules 114: 1345-1353.https://doi.org/10.1016/j.ijbiomac.2018.02.146

45. Li L, Shi ZN, Zhu HY, Hong W, Xie FW, Sun KK (2016) Adsorption of azo dyes from aqueous solution by the hybrid MOFs/GO. Water Sci Technol 73: 17281737.https://doi.org/10.2166/wst.2016.009

46. Ptaszkowska-Koniarz M, Goscianska J, Pietrzak R (2017) Adsorption of dyes on the surface of polymer nanocomposites modified with methylamine and copper(II) chloride. J Colloid Interf Sci 504: 549-560.https://doi.org/10.1016/j.jcis.2017.06.008

47. Ahmad ZU, Yao LG, Wang J, Gang DD, Islam F, Lian QY, Zappi ME (2019) Neodymium embedded ordered mesoporous carbon (OMC) for enhanced adsorption of sunset yellow: Characterizations, adsorption study and adsorption mechanism. Chem Eng J 359: 814826.https://doi.org/10.1016/j.cej.2018.11.174

48. Coros M, Socaci C, Pruneanu S, Pogacean F, Rosu MC, Turza A, Magerusan L (2020) Thermally reduced graphene oxide as green and easily available adsorbent for Sunset yellow decontamination. Environ Res 182.https://doi.org/10.1016/j.envres.2019.109047

49. Senol ZM, Gursoy N, Simsek S, Ozer A, Karakus N (2020) Removal of food dyes from aqueous solution by chitosan-vermiculite beads. International Journal of Biological Macromolecules 148: 635-646.https://doi.org/10.1016/j.ijbiomac.2020.01.166

50. Mirzajani R, Karimi S (2019) Ultrasonic assisted synthesis of magnetic Ni-Ag bimetallic nanoparticles supported on reduced graphene oxide for sonochemical simultaneous removal of sunset yellow and tartrazine dyes by response surface optimization: Application of derivative $\begin{array}{llll}\text { spectrophotometry. } & \text { Ultrason } & \text { Sonochem }\end{array}$ 250.https://doi.org/10.1016/j.ultsonch.2018.09.022

51. Makrygianni M, Lada ZG, Manousou A, Aggelopoulos CA, Deimede V (2019) Removal of anionic dyes from aqueous solution by novel pyrrolidinium-based Polymeric Ionic Liquid (PIL) as adsorbent: Investigation of the adsorption kinetics, equilibrium isotherms and the adsorption mechanisms involved. Journal of Environmental Chemical Engineering 7.https://doi.org/10.1016/j.jece.2019.103163

52. Zhang MM, Zhang SX, Liu XX, Chen H, Ming YF, Xu Q, Wang ZH (2019) One-pot synthesis of multi-functional and environmental friendly tannic acid polymer with $\mathrm{Fe} 3+$ and formaldehyde as double crosslinking agents for selective removal of cation pollutants. Environ Sci Pollut R 26: 31834-31845.https://doi.org/10.1007/s11356-019-06297-2 


\section{Supplementary Files}

This is a list of supplementary files associated with this preprint. Click to download.

- GraphicalAbstract.docx 